\title{
APRENDIZAGEM EXPERIENCIAL NO PROCESSO DE CRIAÇÃO DE EMPRESAS
}

Monique Galvão De França ${ }^{1}$

Kleber Domingos De Araújo ${ }^{1}$

Maria Salete Batista Freitag ${ }^{1}$

${ }^{1}$ Universidade Federal de Goiás 


\section{APRENDIZAGEM EXPERIENCIAL NO PROCESSO DE CRIAÇÃO DE EMPRESAS}

Resumo: Empresas iniciantes, de base tecnológica, com visão empreendedora atuando numa concepção de novos modelos de negócios são cada vez mais comuns no mercado. Neste sentido, a pesquisa objetiva evidenciar a presença da modalidade de aprendizagem experiencial inserida na criação das startups de base tecnológica. Para isso, foi desenvolvida uma investigação qualitativa descritiva adotando o estudo de multicasos. Os dados foram coletados por meio de entrevistas e foi realizada uma análise interpretativa das informações coletadas. Os resultados indicam que a modalidade de aprendizagem pela experiência permeou as fases de preparação e de lançamento dos empreendimentos pesquisados. Futuras pesquisas podem ser realizadas para avaliar, por exemplo, se o aprendizado pela experiência é fator determinante para o fracasso ou sucesso do negócio.

Palavras-chave: Startup. Aprendizagem pela experiência. Criação de empresas. Empresas de base tecnológica.

\section{Introdução}

Empresas nascentes têm inúmeras dificuldades para estabelecer-se em seus mercados: desde o desconhecimento de especificidades regulatórias de seu setor, até a falta de experiência em lidar com clientes e aspectos técnicos dos produtos ou serviços ofertados (MIZUMOTO; ARTES; LAZZARINI; HASHIMOTO \& BEDÊ, 2008). Espera-se que empreendedores com experiência em negócios anteriores tenham mais competências do que os iniciantes, pois tais habilidades e conexões poderiam dar-lhes alguma vantagem, como por exemplo, a obtenção do investimento de capital de risco (ZHANG, 2011).

Segundo Cassar e Graig (2009) a maioria das ações e investimentos realizados por indivíduos na tentativa de iniciar um novo negócio são perdidas, e mesmo que esse processo mal sucedido resulte em custos de tempo, emocional e financeiro, a literatura argumenta que tais indivíduos se beneficiam com a aprendizagem obtida. Nesse sentido, os autores apontam que eles aprendem com os erros, com seus pontos fortes e fracos em diferentes tarefas de risco, avaliando sua própria capacidade de prever oportunidades em empreendimentos futuros e, principalmente, melhorar suas habilidades.

Uma startup é uma empresa iniciante que demonstra possuir características próprias e um modelo diferenciado de negócio. Vários estudos tem procurado investigar os aspectos que as diferenciam das organizações tradicionalmente conhecidas, para entender os fatores determinantes de sucesso desse empreendimento. Desse modo, atuando em condições de

Organizadores:

FGV EAESP

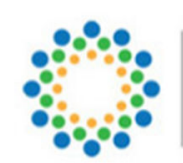

ANEGEPE

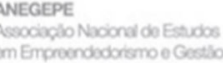
om Enpromondodorsmo o Geeth
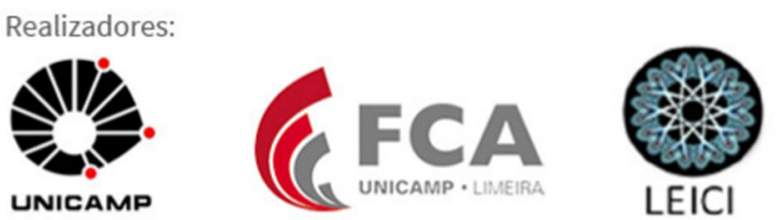
extrema incerteza (RIES, 2012), explorando novas oportunidades (GIARDINO et al., 2014) e construindo uma visão empreendedora (FILION, 1991; CROWNE, 2002), observa-se que as startups precisam criar mecanismos de sobrevivência e crescimento, bem como o desenvolvimento de competências organizacionais. Ademais, a aprendizagem organizacional tem como pressuposto básico o desenvolvimento de estratégias e procedimentos a serem construídos continuamente que, para se atingir melhores resultados, conta-se com a participação efetiva das pessoas no processo de aquisição e disseminação de conhecimento (BITENCOURT, 2001). Todavia, descrever ou definir o processo de aprendizagem se torna uma discussão difícil. Nessa concepção, há argumentos que definem a aprendizagem no contexto empreendedor como o desenvolvimento de conhecimentos necessários para ser eficaz na criação e gestão de empreendimentos (POLITIS, 2005).

Nesse sentido, observa-se que pouca atenção tem sido dada ao estudo de como os empresários, através de suas experiências, desenvolvem conhecimento empresarial, permitindo-lhes reconhecer e agir sobre oportunidades empresariais, organizando e gerindo novos empreendimentos (POLITIS, 2005). Por sua vez, há ainda a necessidade de investigar como o conhecimento adquirido impacta positivamente o desempenho do empreendimento.

No âmbito organizacional, as empresas startups se mostram como embriões empresariais que merecem atenção e investigação acerca das relações de aprendizado presentes, ou passíveis de identificação durante o processo de criação e desenvolvimento.

Neste contexto, este trabalho procura resposta para a seguinte questão: qual o lugar da aprendizagem experiencial no processo de criação de startups de base tecnológica?

O objetivo desta pesquisa consiste em buscar evidências de aprendizagem experiencial no processo de criação de startups de base tecnológica.

O trabalho está desenvolvido em seis seções, iniciando com esta introdução. A segunda seção discorre sobre a fundamentação teórica e com as subdivisões em conceitos de startups e aprendizagem pela experiência. Em seguida, apresenta-se a metodologia da pesquisa, análise de dados e, na sequência, as considerações finais.

\section{Referencial Teórico}

\subsection{Startups - conceitos e processo de criação}

A definição, o entendimento e a compreensão das startups têm sido observados por diferentes lentes. De acordo com Blank e Dorf (2014), uma startup não é uma versão menor de uma grande companhia, mas uma organização temporária em busca de um modelo de negócio escalável, recorrente e lucrativo.

Ries (2012) define startup como sendo uma instituição humana projetada para criar novos produtos e serviços sob condições de extrema incerteza, partindo do pressuposto que, como instituição, a startup requer um novo tipo de gestão, constituída especificamente para o ambiente incerto no qual atua.

Segundo Giardino, et al., (2014), como características essenciais, num conceito recentemente utilizado, startup é uma pequena empresa que explora novas oportunidades de negócios, trabalhando para resolver um problema onde a solução não é bem conhecida, com mercado altamente volátil, de alta incerteza e rápida evolução. Os autores também enumeram

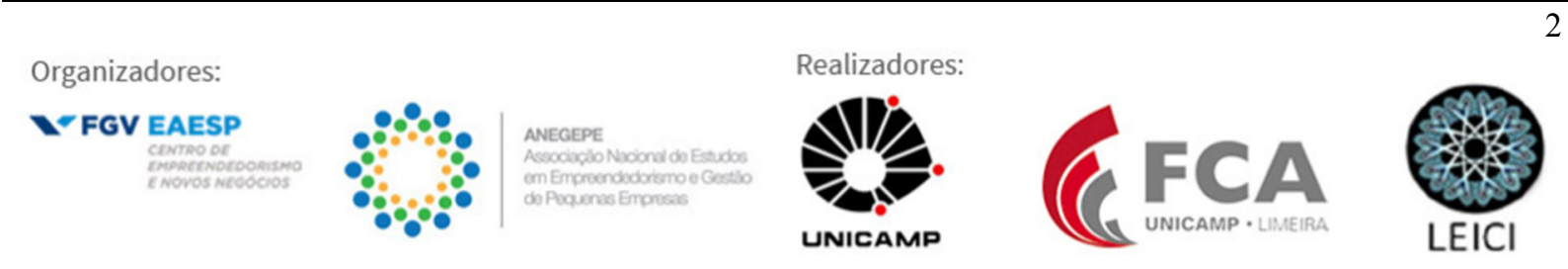


outras características das startups, tais como: possuem recursos escassos; são reativas ao mercado e inovadoras; desempenham suas ações em um mercado incerto; evoluem rapidamente; sofrem pressão do tempo e certa dependência de terceiros; iniciam com uma equipe pequena e de baixa experiência; trabalham em um único produto e possuem, inicialmente, ausência de base de cultura organizacional.

$\mathrm{Na}$ mesma linha, Sutton (2000) caracterizando as startups, enumera quatro atributos principais observáveis: juventude e imaturidade; possuir recursos limitados; tecnologias e mercados dinâmicos; e, principalmente, sofrer influência de investidores, clientes, parceiros e concorrentes.

O ciclo de vida de uma startup é definido por Blank (2015) como sendo: pesquisa, construção e crescimento. Segundo o autor, a fase de pesquisa consiste na busca pela startup do seu modelo de negócio repetível e escalável, o que leva normalmente a vários protótipos do seu produto até encontrar um que se adéque ao seu mercado. Em seguida, tem-se a fase de construção que consiste em estabelecer uma cultura de gestão necessária para evoluir e ganhar rentabilidade. Por fim, na fase de crescimento, após atingir liquidez, pode-se formalizá-la juridicamente, abrir capital, exigindo pela gestão um conjunto mais avançado de procedimentos, indicadores e processos.

Crowne (2002) define a fase de início das empresas de base tecnológica como o período entre a concepção do produto e a primeira venda, na qual todas começam com a visão empreendedora de um mercado de oportunidades, tornando necessária a formação de uma equipe executiva com habilidades para construir o produto. A fase seguinte é a de estabilização, que inicia-se com a primeira venda até à estabilidade do produto, quando torna-se capaz de despertar a atração do mercado, gerando crescimento; e por último, a maturidade, fase cujo crescimento e a participação no mercado da empresa estão consolidados. Desta forma, tanto Blank (2015) quanto Crowne (2002) concordam que uma startup passa por um processo gradual de evolução.

$\mathrm{Na}$ construção de uma empresa de base tecnológica, o fundador de startup organiza um grupo de pessoas com diversas especializações, busca acesso ao capital e a outros recursos, agindo como um gerente para implementar o seu plano de negócio, necessitando de uma ampla gama de competências para o exercício de suas atividades empreendedoras. Como consequência, a experiência vivenciada pelo criador da startup possibilita uma oportunidade de trabalhar com pessoas, investidores, profissionais, especialistas diversos, fornecedores e clientes, caracterizando uma rede de conhecimentos (ZHANG, 2011).

No modelo de negócio, Chesbrough (2007), avalia que cada empresa tem o seu próprio modelo, cujo objetivo é a criação e captura de valor, dentre as quais suas funções são: i) articular a proposição de valor; ii) identificar um segmento de mercado a quem se dirigir e definir a estrutura de cadeia de valor; iii) especificar o mecanismo de geração de receita; iv) descrever a posição da empresa na rede, ou ecossistema e, por fim, formular estratégias competitivas e inovadoras.

Com o objetivo de implementar seu modelo de negócio a empresa planeja suas ações. $\mathrm{Na}$ concepção do planejamento de um sistema de aprendizagem empresarial em que Filion (1991) define empreendedor como aquele que concebe, desenvolve e realiza visões, tal processo implica na busca de conhecimento de forma contínua e proativa em prol do objetivo traçado.

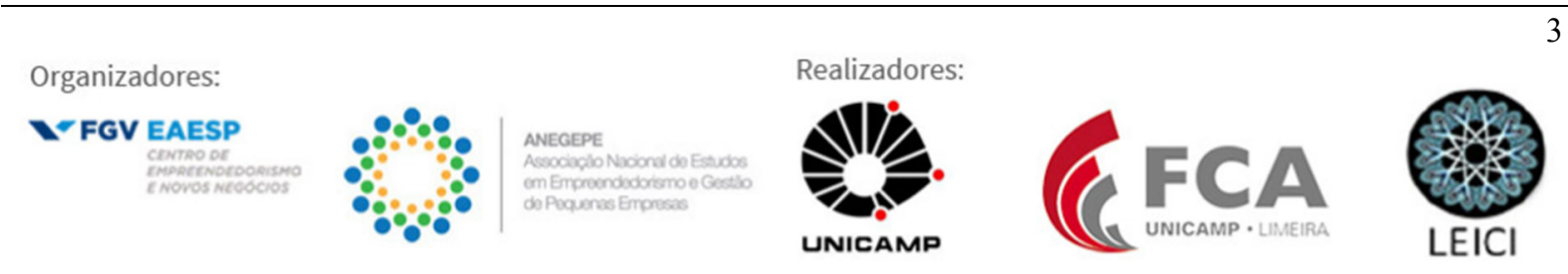


Mas antes, o empreendedor terá desenvolvido sua visão de negócio. Estudos anteriores, como de Van de Ven, Hudson e Schroeder (1984), examinaram, sob os aspectos organizacionais, fatores que influenciam o sucesso do negócio startup. Tais fatores, encontrados pelos autores, são: o nível de conhecimento e experiência do empreendedor, ideia clara do negócio e a capacidade que o empreendedor tem de envolver no seu plano organizacional uma mobilização coletiva das pessoas envolvidas.

Borges, Filion e Simard (2008), pesquisando o processo de criação de empresas por jovens empreendedores, definem o processo como o conjunto de atividades que $\mathrm{o}$ empreendedor realiza para conceber, organizar e lançar uma empresa. Os autores sintetizaram um quadro contendo as atividades mais citadas pela literatura (Quadro 1):

Quadro. 1.Etapas e atividades do processo de criação de empresas.

\begin{tabular}{|c|c|c|c|c|}
\hline 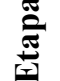 & Iniciação & Preparação & Lançamento & Consolidação \\
\hline 莺 & $\begin{array}{ll}\text { - } & \text { Identificação da } \\
\text { oportunidade de } \\
\text { negócio. } \\
\text { - } \\
\text { Reflexão e } \\
\text { desenvolvimento } \\
\text { da ideia de } \\
\text { negócio. } \\
\text { - Decisão de criar a } \\
\text { empresa. }\end{array}$ & $\begin{array}{ll}\text { - } & \text { Redação do plano } \\
\text { de negócios. } \\
\text { - } & \text { Realização do } \\
\text { estudo de mercado. } \\
\text { - } & \text { Mobilização de } \\
\text { recursos } \\
\text { financeiros. } \\
\text { - Constituição da } \\
\text { equipe } \\
\text { empreendedora. }\end{array}$ & $\begin{array}{ll}\text { - } & \text { Constituição legal } \\
\text { da empresa. } \\
\text { - } & \text { Organização das } \\
\text { instalações e dos } \\
\text { equipamentos. } \\
\text { - } \\
\text { Desenvolvimento } \\
\text { do primeiro } \\
\text { produto ou serviço. } \\
\text { - Contratação de } \\
\text { empregados. } \\
\text { Realização da } \\
\text { primeira venda. }\end{array}$ & $\begin{array}{ll}\text { - } & \text { Realização de } \\
& \text { atividades de } \\
\text { promoção e } & \\
\text { marketing. } \\
\text { - } \quad \text { Comercialização de } \\
\text { produtos e serviços. } \\
\text { - Alcance do ponto de } \\
\text { equilíbrio. } \\
\text { - } \quad \text { Planificação formal. } \\
\text { Gestão da nova } \\
\text { empresa. }\end{array}$ \\
\hline
\end{tabular}

Fonte: Adpatado de Borges, Filion e Simard (2008)

Nas quatro etapas do modelo (Quadro 1), o empreendedor passa necessariamente por um conjunto de experiências que resulta em aprendizagens fundamentais para a gestão do negócio startup.

Neste sentido, Arruda, Nogueira, Cozzi e Costa (2012) evidenciam que as startups apresentam características particulares, tanto no que diz respeito aos seus objetivos, desde sua criação, quanto ao contexto no qual são criadas e se desenvolvem, em uma nova forma de empreender, de modo diferente do que era conhecido até a década dos anos de 1990.

Essa nova forma de empreender foi observada por Ries (2012), de forma quase poética, pois eleva o status das startups ao inferir que elas não existem apenas para fabricar coisas, atender clientes e gerar lucros, mas sim, para aprender a desenvolver um negócio sustentável, cuja aprendizagem pode ser validada cientificamente por meio de experimentos frequentes. Tais experimentos, segundo o autor, permitem aos empreendedores testar sua percepção, cujo cerne do seu projeto definido como Lean Startup preconiza a visão de: construir, medir e aprender, num contínuo ciclo de feedback junto ao cliente.

Conforme referenciado, é possível neste ponto estabelecer relação do processo de criação das startups com a aprendizagem pela experiência que constitui uma das modalidades

\section{Organizadores:}

FGV EAESP

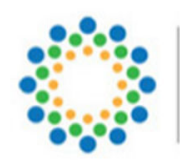

ANEGEPE
Associaglo t Sidos
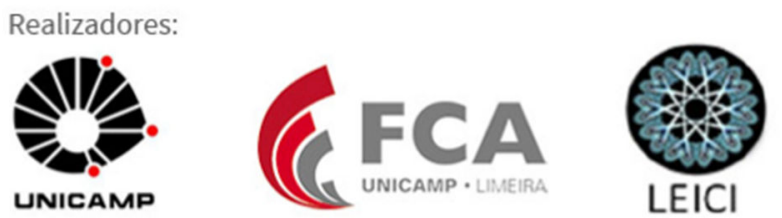
de aprendizagem organizacional. Conforme preconizando por essa modalidade, o aprendizado quando fruto de tentativas e erros mostra-se mais eficaz do que a simples repetição dos acertos (ARRUDA; NOGUEIRA; COZZI \& COSTA, 2012). Neste cenário, a realidade da maioria das startups é o fracasso, e grande parte dos novos produtos não faz sucesso, e os novos empreendimentos não alcançam seu potencial máximo (RIES, 2012). Assim, denota-se que erros e fracassos podem inter-relacionar-se no processo de criação e desenvolvimento das startups, tendo em vista a dinâmica de adequação dos esforços e recursos na geração do produto.

\subsection{Aprendizagem pela experiência nas ações de empreendedorismo}

Na definição de Bitencourt (2001), a aprendizagem reflete uma resposta alternativa às mudanças enfrentadas pelas empresas, na qual se busca desenvolver a capacidade de aprender continuamente a partir de experiências organizacionais e a traduzir estes conhecimentos em práticas que contribuam para um melhor desempenho, tornando a empresa mais competitiva.

A aprendizagem pela experiência pode ser entendida principalmente nas dimensões de conteúdo, incentivo e interação, envolvidas em uma forma equilibrada e substancial, onde quanto mais complexo for o tipo de aquisição individual, mais provável seria a caracterização como experiencial (ILLERIS, 2007). Aprender através da experiência é um processo contínuo individual, um fenômeno dinâmico e extremamente complexo (COPE; WATTS, 2000).

$\mathrm{Na}$ definição do conceito de experiência, Gasque (2008) o faz apresentando-o sob três pilares fundamentais: linguagem, atenção consciente e interação de corpo, mente e ambiente, indo ao encontro da visão de Pimentel (2007), onde esclarece que aprender pela experiência não significa qualquer vivência, mas aquela na qual há a transformação em aprendizagem. Isso significa que o processo de apendizagem se dá pela apropriação dos saberes num processo contínuo de ação e reflexão.

Politis (2005) explica que a aprendizagem tem sido apresentada como um processo experiencial onde a experiência de um empresário é transformada em conhecimento, que por sua vez pode ser usado para orientar a escolha de novas experiências. A obtenção de experiências e o desenvolvimento de novos conhecimentos podem ser transformados em conhecimento experiencial adquirido (KOLB, 1984).

Sendo assim, retomando a teoria da aprendizagem pela experiência, Kolb (1984) reflete sobre três modelos importantes da aprendizagem, Lewin, Dewey e Piaget e apresenta sua própria formulação do que ele chama de características do aprendizado pela experiência. Em sua visão, o aprendizado é concebido como um processo e não como resultado em si, é contínuo e imerso em experiência que requer a resolução de conflitos entre a racionalidade dialética oposta nos modos de adaptação do mundo, bem como um processo holístico de adaptação do mesmo, envolvendo transações entre pessoas e ambiente, e por fim um processo de criação de conhecimento.

Da mesma forma que Kolb (1984) apresenta o conhecimento gerado na aprendizagem como um processo continuamente criado e recriado, Pimentel (2007) analisa aprendizagem experiencial como processo contínuo de ação e reflexão, partindo de uma proposição de que todo desenvolvimento profissional decorre da aprendizagem atualmente adquirida, assim como o desenvolvimento já constituído se torna imprescindível para o aprendizado.

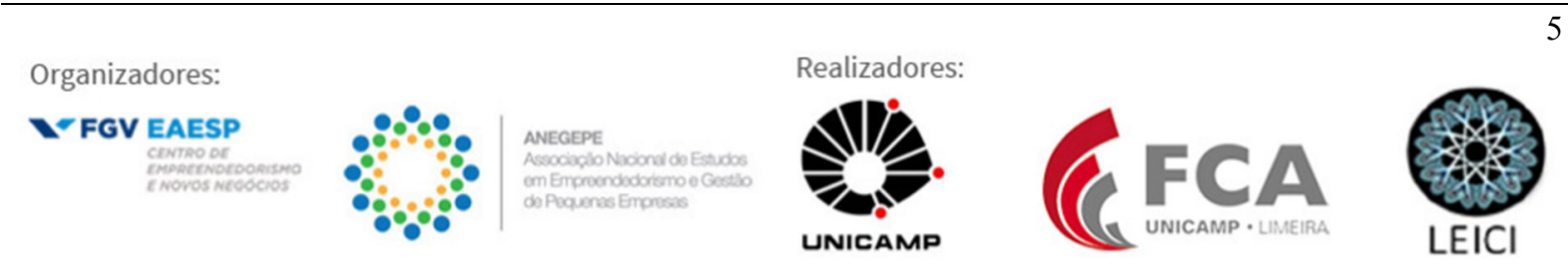


A capacidade do indivíduo de refletir, controlar e monitorar seus próprios processos, seus valores pessoais, motivações, crenças, visão crítica e atitudes éticas e responsáveis abrangem o desenvolvimento da competência da busca, análise e compreensão da informação, que é realizada de acordo com necessidades individuais (GASQUE, 2008). Nesse sentido, é possível inferir que em um processo de aprendizagem experiencial o indivíduo está inserido em um círculo de ação e reflexão, expressando assim sua capacidade de compreender e desenvolver suas competências individuais.

Nas abordagens cognitivas, é central a maneira como os indivíduos processam a informação, sendo que as características cognitivas dizem respeito às diferenças em atribuições e percepções (GELDEREN; TURIK \& BOSMA, 2006). Gatewood, Shaver e Gartner (1995) pesquisaram se a orientação cognitiva influenciaria na persistência da atividade organizacional. O processo cognitivo é visto como uma construção dinâmica do mundo, e por isso inseparável do histórico de vida e do processo de viver (GASQUE, 2008). A compreensão da história de vida dos empreendedores ganhou espaço na pesquisa de Rae (2000) que se preocupou em compreender como se dá o desenvolvimento empresarial através da aprendizagem, caracterizando uma verdadeira descoberta de identidade.

Dentre as características do comportamento do empreendedor, Filion (1999) evidencia que o empreendedor desenvolve um alto nível de consciência do ambiente no qual vive, usandoo para detectar oportunidades de negócios, vivendo um processo de evolução constante, buscando sempre o aprendizado no exercício de sua atividade empreendedora.

Nas pequenas empresas, avalia Breslin (2012), que o comportamento da organização é dominado pelo empreendedor e consequentemente as ideias, conhecimentos, competências e rotinas vão evoluindo ao longo do tempo. Por outro lado, segundo o autor, os empresários também aprendem através de experiências de erro e interpretação do feedback do ambiente, desenvolvendo representações cognitivas, permitindo-lhes identificar novos relacionamentos e oportunidades, ensejando o desenvolvimento de habilidades e novos conhecimentos. $\mathrm{O}$ empreendedor passa a socializar o conhecimento adquirido, surgindo as experiências coletivas e a identidade de grupo.

Politis (2005) revitaliza a compreensão da aprendizagem empresarial como um processo experimental apresentando uma estrutura conceitual determinada, dentre outras coisas, em investigar a ligação entre a experiência de carreira dos empresários e o desenvolvimento do conhecimento empresarial, focado nos pilares de: experiência de carreira (tanto administrativa como operacional); reconhecimento de oportunidades; processo de transformação e fatores que o influenciam; e transformação de resultados de eventos anteriores. Tal estrutura se mostra completa quando se observa as características de reconhecimento de oportunidades, observadas por Filion (1991), ao mesmo tempo que agrega experiências adquiridas através da carreira anteriormente exercida, junção de aptidão empreendedora e experiência vivida.

Cope e Watts (2000) analisaram o processo de aprendizagem dos empreendedores em relação ao processo de desenvolvimento pessoal e empresarial com base nas teorias da aprendizagem e do ciclo de vida dos negócios, discutindo o impacto de pontos críticos do indivíduo, em particular o seu papel na aprendizagem empresarial. Focalizaram na pesquisa as recordações pessoais do empreendedor, buscando identificar a sensação deste ao abrir um negócio, assim como a descrição dos melhores e piores tempos passados, momentos de crises chamados de incidentes críticos, e o quanto isso muda a maneira de como faz as coisas

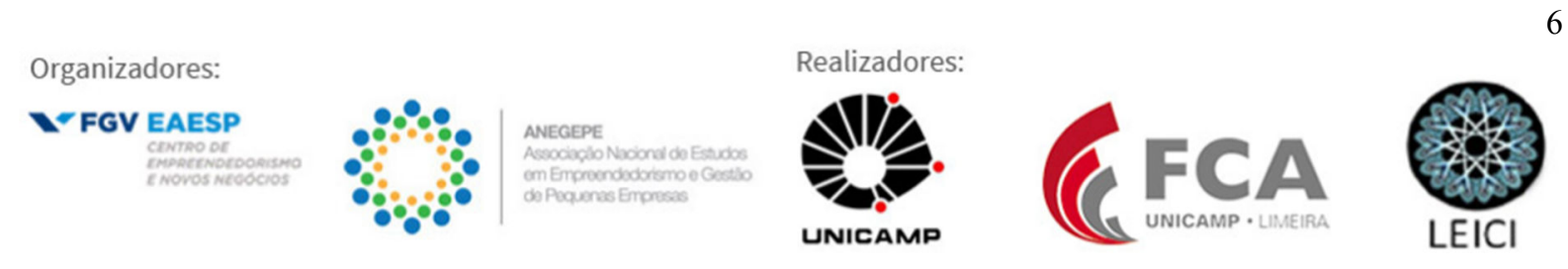


atualmente. Desta forma, deram espaço para a descrição de momentos marcantes e de grande importância para os empreendedores, aproximando assim o pesquisado das suas experiências vividas.

Em sua pesquisa, Rae (2000) apresentou, de acordo com uma vasta literatura, um modelo estruturado nos temas: personalidade empreendedora; desenvolvimento de carreira empresarial; a formação em empreendedorismo e abordagem cognitiva da aprendizagem empresarial. Trouxe à tona o modo de como as pessoas usam temas e recursos linguísticos para falar de sua aprendizagem em um relato narrativo. Seus achados sugerem que as pessoas desenvolvem um modelo mental como ponto de partida na criação de valor para que elas possam usar e fazer sentido em suas próprias ideias e experiências, de forma que o discurso empreendedor se enquadre como teoria viva.

Em sua pesquisa, Lima (2016) buscou investigar a aprendizagem no processo de decisão estratégica em equipes de direção de pequenas empresas de base tecnológica, cujos resultados mostraram que o comportamento dos dirigentes é mais compatível com a aprendizagem em si do que com processos formais, como por exemplo, projeções numéricas e cenários futuros, e que o aprendizado coletivo proporcionou a essas empresas capacidade de reagir às ameaças e oportunidades do mercado competitivo.

Conforme delineado, diversos estudos teóricos e empíricos buscaram tanto evidenciar as características presentes quanto verificar o modo de como ocorre o processo de aquisição da aprendizagem experiencial pelos empreendedores na atividade organizacional. Nesse sentido, a literatura abre caminhos para este estudo sobre a influência desta modalidade de aprendizagem no processo de criação das startups.

\section{Metodologia}

O presente trabalho apresenta uma abordagem descritiva, de cunho qualitativo. Para Roesch (1999, p.137) As pesquisas descritivas "buscam informação necessária para a ação ou predição [...], não respondem bem o porquê, embora possam associar certos resultados a grupos de respondentes".

Trata-se de um estudo de casos múltiplos, com entrevista semiestruturada adotada para coleta dos dados. Justifica-se a escolha pelo objetivo de perceber aprendizagem experiencial no processo de criação das startups. De acordo com Yin, (2001) esse tipo de estudo colabora no levantamento de evidências expressivas ensejando maior confiabilidade quando comparado aos estudos de casos únicos. A pesquisa qualitativa não procura enumerar, ou medir os eventos estudados. Envolve a obtenção de dados descritivos sobre pessoas, lugares e processos interativos pelo contato direto do pesquisador com a situação estudada (Godoy, 1995).

De acordo com Triviños (2006), o estudo de caso tem por objetivo aprofundar a descrição de determinada realidade. E apesar de não permitir generalizações, fornece conhecimento aprofundado de uma realidade delimitada que os resultados atingidos podem permitir e formular hipóteses para o encaminhamento de outras pesquisas.

As empresas escolhidas estão entre as participantes do grupo formado no ecossistema goiano, StartupGO, cujo envolvimento se dá em torno de atividades voltadas ao empreendedorismo e fomento local da atividade de base tecnológica.

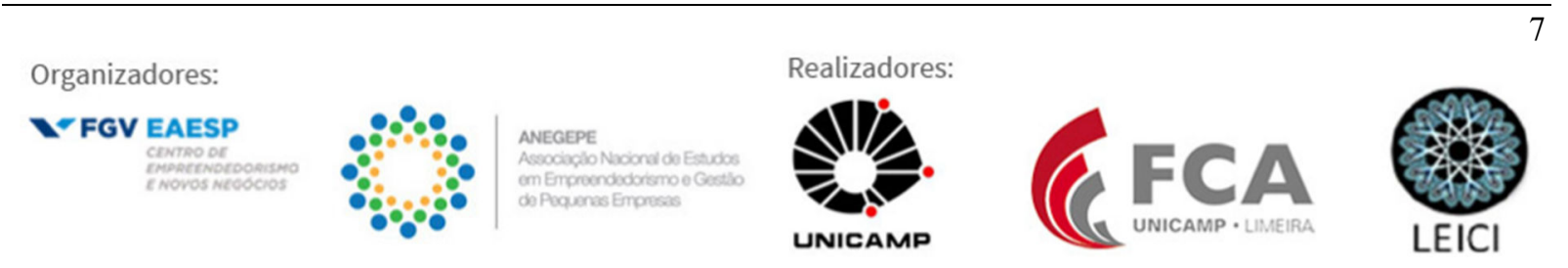


Para estruturação do instrumento de coleta como também para a análise dos dados foi adotado o modelo de Borges, Filion e Simard (2008), cujo estudo apresenta as etapas e atividades do processo de criação de empresas. Durante a coleta, foi explicado aos entrevistados o objetivo da pesquisa e em que consiste cada fase do processo de criação da empresas.

Desta forma, as perguntas orientadoras das entrevistas estão divididas em duas partes num total de 10 perguntas. A primeira parte é composta de três perguntas com relação ao perfil das empresas respondentes contemplando tempo de existência atual, em qual etapa se encontra quantos são os membros da equipe e quantos dela são fundadores. E, para conhecer a experiência dos fundadores foi indagado se estes já haviam participado da criação de startup ou outro empreendimento anteriormente e se obtiveram sucesso ou falharam.

$\mathrm{Na}$ segunda parte da entrevista, realizada com base no modelo de Borges, Filion e Simard (2008) foram desenvolvidas 7 perguntas divididas em 4 blocos, conforme Quadro 2 a seguir:

Quadro. 2. Suporte teórico das perguntas formuladas.

\begin{tabular}{|c|c|c|c|}
\hline Blocos & & Perguntas & Base teórica \\
\hline Iniciação & & $\begin{array}{l}\text { Qual foi a visão ou oportunidade de negócio } \\
\text { vislumbrada e seu fator motivacional? }\end{array}$ & $\begin{array}{l}\text { Filion (1991, 1999); Breslin } \\
\text { (2012). Ries(2012); Blank e } \\
\text { Dorf (2014) }\end{array}$ \\
\hline Preparação & $\begin{array}{l}\text { 2) } \\
\text { 3) }\end{array}$ & $\begin{array}{l}\text { No desenvolvimento do seu modelo de } \\
\text { negócio, quais conhecimentos e experiências } \\
\text { anteriores lhe ajudaram e quais lhe faltaram } \\
\text { que você teve que buscar nesta etapa? } \\
\text { Nesta fase de preparação sua equipe já se } \\
\text { encontrava alinhada com os objetivos do } \\
\text { projeto? }\end{array}$ & $\begin{array}{l}\text { Cope e Watts (2000); Rae } \\
\text { (2000); Politis (2005) }\end{array}$ \\
\hline Lançamento & 4) & $\begin{array}{l}\text { No desenvolvimento do seu produto ou } \\
\text { serviço você buscou feedback junto ao } \\
\text { cliente, público alvo? Se o fez, foi relevante } \\
\text { para se ajustar ao mercado? } \\
\text { Qual foi a aprendizagem experiencial } \\
\text { adquirida nesta etapa? }\end{array}$ & $\begin{array}{l}\text { Ries (2012); Blank e Dorf } \\
(2014) \\
\text { Cope e Watts (2000); Rae } \\
\text { (2000) Politis }(2005)\end{array}$ \\
\hline Consolidação & & $\begin{array}{l}\text { Após ter passado pelo processo de criação da } \\
\text { startup, você acredita ter aprendido pela } \\
\text { experiência vivenciada no negócio? Como } \\
\text { você descreveria? } \\
\text { Você acredita que o aprendizado pela } \\
\text { experiência é preponderante no processo de } \\
\text { criação da startup? }\end{array}$ & Kolb (1984) \\
\hline
\end{tabular}

Fonte: Elaboração própria.

\section{Análise e discussão dos resultados}

A análise interpretativa das entrevistas ocorreu considerando a estrutura da vivência apresentada pelos sujeitos em suas falas, denotando significados de diferentes elementos que 
ensejam a aprendizagem, como por exemplo: resolução de conflitos; processos contínuos e descontínuos; adaptação ao cotidiano, conteúdo, incentivo e interação; reflexão e controle de seus próprios processos; reconhecimento de oportunidades (nível de consciência); persistência na atividade organizacional; formar e mobilizar o capital social; socialização do conhecimento (experiências coletivas) mostrando, assim, significados dos aspectos da realidade para os sujeitos (SANBERG, 2000).

Foram entrevistados 4 empresários escolhidos aleatoriamente no grupo StartupGO formado por empreendedores que compartilham conhecimentos, informações, experiências, trabalho, enfim uma rede social local. O Quadro 3 apresenta o perfil dos empreendedores entrevistados.

\subsection{Perfil dos entrevistados}

Os dados obtidos são reveladores de alguns elementos que caracterizam as empresas startups, conforme Quadro 3, seguido de sua análise.

Quadro 3: Perfil das empresas.

\begin{tabular}{|l|l|l|l|l|}
\hline Casos & Tempo de constituição & $\begin{array}{l}\text { Número de } \\
\text { fundadores }\end{array}$ & $\begin{array}{l}\text { Etapa no processo } \\
\text { de criação }\end{array}$ & $\begin{array}{l}\text { Experiências } \\
\text { anteriores }\end{array}$ \\
\hline Caso 1 & 6 a 8 meses & 2 & Preparação & Sim \\
\hline Caso 2 & 1 ano & 2 & Lançamento & Sim \\
\hline Caso 3 & 4 meses & 2 & Preparação & Não \\
\hline Caso 4 & 1 ano e 4 meses & 1 & Lançamento & Sim \\
\hline
\end{tabular}

Fonte: Elaboração própria.

Pelo perfil das empresas investigadas verifica-se que a empresa mais nova tem 4 meses e a mais velha 1 ano e 4 meses. Das 4 pesquisadas, apenas uma tem um único fundador e as demais são compostas de 2 sócios fundadores.

Outra característica importante na avaliação do perfil é sobre a experiência anterior dos empreendedores tanto em startups quanto em outro negócio, pois as respostas indicam que em apenas uma das empresas o empreendedor não teve participação anterior em startups, porém disseram que atuaram no ramo empresarial tradicionalmente conhecido. Com relação à etapa em que se encontra cada empreendimento, a literatura em Borges, Filion e Simard (2008) não relaciona as etapas ao tempo de existência e sim às atividades. Cada empresa se auto classificou a partir da explicação das etapas de criação, desta forma, as duas mais novas em preparação, e as outras duas na etapa de lançamento, confirmando pelo tempo de existência informado, que se trata de empreendimentos jovens.

\subsection{Aprendizagem pela experiência nos casos em estudo}

\subsubsection{Caso 01: Fase de Preparação}

A análise está fundamentada nas respostas do entrevistado 01, buscando aderência teórica que consubstancia a interpretação qualitativa dos resultados. $\mathrm{O}$ respondente do caso 01 considera que sua empresa está na fase de preparação, sendo as suas evidências relacionadas a

Organizadores:

FGV EAESP
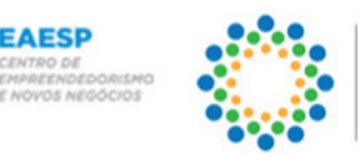

ANEGEPE

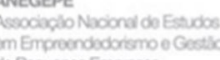
am Emproendodonismoe Gectit
do Pequenas Enpreses
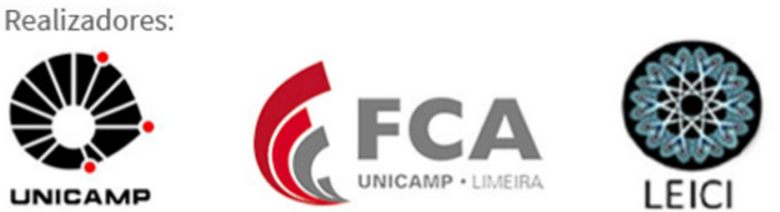
experimentos e validações, e realização de ajustes no produto. Todavia, ele já realizou comercializações, pois há citação de fusão de empresas relacionadas a produtos. Conforme uma das falas: “(...) foi feita uma fusão com a Rádio Táxi e a Porto Seguro (...) e considero um caso de sucesso." Entretanto, não há uma evidência mais consistente da estabilidade na fase de consolidação, mas de transição entre o lançamento e a consolidação (BORGES; FILION; SIMARD, 2008).

Observou-se que está presente a relação de sucesso e fracasso, pois o empreendedor, com 20 anos de trabalho com empresas de tecnologia vivenciou por várias vezes essa realidade. Em uma das falas o empreendedor relata que: “(...) outros projetos iniciados, outras startups iniciadas que fracassaram foram várias (...)". Nesse aspecto, salienta-se a presença da experiência com o foco no aprendizado organizacional (ARRUDA NORGUEIRA, COZZI \& COSTA, 2012; CASSAR \& GRAIG, 2009).

Outro ponto levantado pelo entrevistado foi a preocupação com a formação do capital social, conforme fala: “(...) formar uma equipe, então um time para tirar do papel.” Esse aspecto de preocupação em formar uma equipe indica aproximação com a modalidade de aprendizado experiencial, delineada por Zhang (2011). Além desse aspecto, foi evidenciado que há uma preocupação voltada para o coletivo, ou seja, de aprendizado coletivo. Tal fato pode ser evidenciado no relato do empreendedor: "(...) o alinhamento da equipe foi acontecendo ao longo do tempo.” O aprendizado coletivo está presente na ótica de Sanderbeg (2000).

Há também a presença dos elementos da variável de processo contínuo (KOLB, 1984), observado na fala: “(...) algumas mudanças que a gente fez no processo”. Se existem mudanças no processo, não tem havido solução de continuidade, logo há a caracterização de processo contínuo na busca de melhoria e aprimoramento que constitui variável de aprendizado organizacional corroborado por Pimentel (2007), que analisa a aprendizagem como processo contínuo de ação e reflexão.

Outro fator evidenciado relaciona-se com a interação, a preocupação com o feedback, conforme pode ser percebido na fala: “(...) com certeza o feedback foi fundamental para fazer os ajustes." Nesse sentido, relaciona-se a variável consciência que também surgiu na fala do entrevistado, na forma de encarar as dificuldades e sucessos: “(...) todas as experiências, eu acredito, são oportunidades de aprendizado".

Portanto, na opinião do entrevistado, as experiências que ele vivenciou são consideradas de forma consciente no processo de aprendizado. Em conformidade com as evidências sugeridas na fala do entrevistado 01 , observou-se também que a construção do aprendizado organizacional está fundamentada na ótica de Politis (2005) no que se refere à orientação para novas escolhas e sob a ótica de um processo contínuo (COPE \&WATTS, 2000; PIMENTEL, 2007).

\subsubsection{Caso 02: Fase de Lançamento}

O empreendedor respondente do caso 02 declarou que a empresa encontra-se na fase de lançamento. Como evidências das variáveis relacionadas, pode-se destacar o desenvolvimento do protótipo do produto e a primeira venda, conforme relatado: “(...) estamos trabalhando no nosso protótipo; (...) os nossos primeiros clientes estão começando a experimentar o nosso produto." Os argumentos estão alinhados com as variáveis previstas por Borges, Filion e Simard

Organizadores:

- FGV EAESP
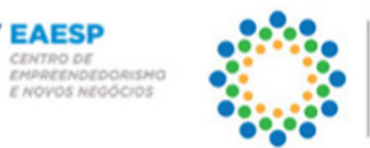

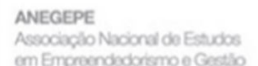

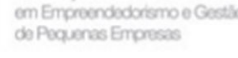

Realizadores:
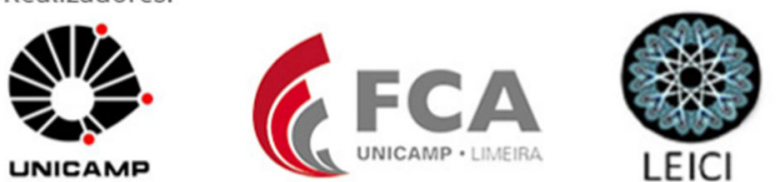
(2008). Considera-se que os recursos utilizados são essênciais e necessários para a fase estabelecida pelo respondente, embora não tenham sido mencionados.

Observa-se que a empresa possui um ano de existência, mas encontra-se avançada quanto ao processo, ou seja, na etapa de lançamento, adequando-se às necessidades do cliente, com o protótipo do produto. Neste sentido, verifica-se também o aprendizado voltado para a relação com o cliente no processo de feedback de Ries (2012).

Como variáveis presentes no processo de aprendizado, foi caracterizada pelo respondente a experiência desenvolvida em outros projetos, de acordo com o relato: “(...) Eu, como desenvolvedor de sistemas, já participei de outros projetos (...) tive sócio durante um período (...) mas acabei não continuando com essa sociedade." A afirmação remete a Cassar e Graig (2009) no que se refere às tentativas de inciar um novo negócio que são perdidas, porém, resultando em novas habilidades aprendidas.

A variável consciência e percepção de oportunidade foram destacadas pelo respondente no momento em que cita que: “(...) O fornecedor atacadista passa por uma dificuldade em expor o seu produto e serviço para o seu cliente." Nesse aspecto, o respondente destacou oportunidades de mercado, relativas ao negócio. De outra forma, destaca a variável consciência como processo cognitivo de percepção de aquisição de habilidades (RAE, 2000; GELDEREN; TURIK \& BOSMA, 2006), conforme fala: “(...) Eu estou bem mais resistente (...), me sinto mais confortável em passar por etapas como abordar clientes, fazer validação, receber feedback (...)."

Diante do exposto pelo entrevistado, pode-se inferir que a adaptação do empreendedor ao processo no qual está inserido, considerando as experiências adquiridas por ele, fez com que se tornasse mais bem preparado e com maior confiança para enfrentar o futuro, como sugerido por Breslin (2012).

A variável persistência na atividade organizacional e processo contínuo (KOLB, 1984; PIMENTEL, 2007) podem ser percebidas na fala do respondente: “(...) O lançamento não acontece em uma única etapa, são várias idas e vindas de apresentar e receber feedback."

Como consequência, há de se considerar também a variável interação, por meio do feedback (RIES, 2012). Outra variável salientada pelo respondente, refere-se a preocupação com a formação do capital social: “(...) A gente, claro, tentava vender a ideia (...) para esse novo intregrante do time." O respondente destaca que ao chegar um novo membro, a formação psicológica de alinhamento e formação do time são fatores considerados pela empresa.

Portanto, o empreendimento do caso 02 , enquadrado na fase de lançamento, evidenciou características vivenciadas durante o seu processo de criação que corrobora com autores que preconizam a aprendizagem experiencial (KOLB, 1984; PIMENTEL, 2007).

\subsubsection{Caso 03: Fase de Preparação}

Com uma equipe reduzida, formada apenas por duas sócias fundadoras, a entrevistada do caso 03 se autodenomina na fase de preparação. O relato apresentado indica uma certa maturidade e persistência na atividade organizacional, pois trata-se da startup de menor tempo de existência da amostra. Segundo a fundadora, tanto ela quanto sua sócia não possuíam nenhuma experiência no ramo de startups, entretanto informaram que ambas possuíam experiência anterior, uma exercendo a advocacia e a outra, como empresária. As atividades

Organizadores:

FGV EAESP

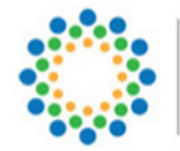

ANEGEPE mencrom

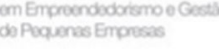
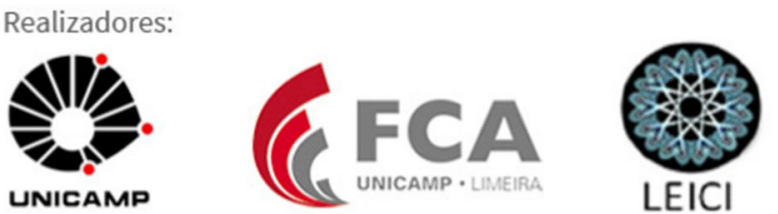
anteriores das fundadoras não se referiam a qualquer ligação com atividades de empresas tecnológicas.

As sócias, mesmo sem qualquer formação e experiência persistiram no negócio, não obstante as dificuldades próprias de conhecer a atividade de base tecnológica, propor respostas e planejar um negócio alheio aos seus conhecimentos. A característica de visão de negócio alinhada com Filion (1999) foi observada, conforme fala: “(...) no início nós tínhamos uma proposta de valor e ao longo dos meses, ela foi sendo modificada, então aquela visão inicial, ela se perdeu e hoje a gente tem uma outra proposta de valor."

Observa-se também que o fator motivacional foi uma solução para uma vivência pessoal das fundadoras, ou seja, buscaram a construção de um negócio cujo produto elas próprias sentiam necessidade no mercado: “(...) então essa questão (...) sempre foi muito legítima pra mim quanto pra minha sócia (...) é uma dor que a gente viveu e vive, de solucionar essa dor." Outra característica importante se refere aos meios formais e informais de obtenção de conhecimento do negócio, denotando a variável socialização do conhecimento (SANBERG, 2000; BRESLIN, 2012).

A empreendedora enfatiza a importância da "bagagem" pessoal, experiência de vida, entretanto destaca que não é o suficiente, pois a busca pelo aprendizado é um exercício contínuo e diário. Esta característica de vivência pessoal é fundamentada por Gasque (2008) e Politis (2005). No relato da fala: “(...) diariamente estamos buscando constantemente nos informar, estudar, nos inteirar, nos envolver nesse ecossistema, e a gente tem buscado mentoria e orientações. Então, o aprendizado é contínuo e diário." Observa-se a influência do mercado no direcionamento do negócio, referendado por Kolb (1984).

$\mathrm{Na}$ sequência, observa-se que para a empresária é fundamental perceber o direcionamento que o mercado dá ao empreendimento, conforme fala: “(...) Nós fomos buscar do mercado resposta para nossa proposta, e a gente voltou e reavaliou a nossa proposta." Por outro lado, o planejamento se faz presente, porém fica evidente que o peso maior é a escuta do cliente, o que denota o processo de feedback sugerido por Ries (2012). Em outro momento, a fala: “(...) O aprendizado é o que você tem que escutar do seu cliente, simplesmente isso.” Esse ponto caracteriza um processo contínuo de construção, pois a respondente demonstra flexibilidade de gestão quando cita que não há apego a formatos, o que há é a necessidade de atender o mercado, assim como sugerido por Pimentel (2007).

Por fim, a entrevistada acredita que o aprendizado não é finito, sempre há algo para se aprender. Percebe-se como aspecto diferenciado sobre a gestão da startup na fala da entrevistada é que além de buscar fontes formais e informais de conhecimento, está presente também a escuta ao cliente e a abertura do empreendedor quanto a possível necessidade de ajuste do produto ou projeto, quando discorre que: “(...) O aprendizado é essencial. Você não pode ignorar o que você aprendeu. Você tem que aprender com seus erros e errando, mesmo diariamente. Você vai errando e consertando o erro até você acertar. É assim que funciona." O processo de se aprender com os erros, pelas tentativas é positivo e contribui para o aprendizado experiencial, fortalecendo a capacidade e a qualidade de gestão. O aprendizado é resultante de erros cometidos e são suportados teoricamente por Arruda, Nogueira, Cozzi e Costa (2012) e Cassar e Graig (2009).

Organizadores:

- FGV EAESP
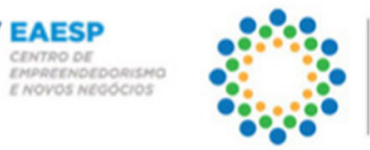

ANEGEPE
Associaglo

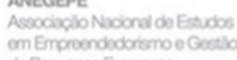

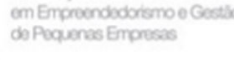

Realizadores:
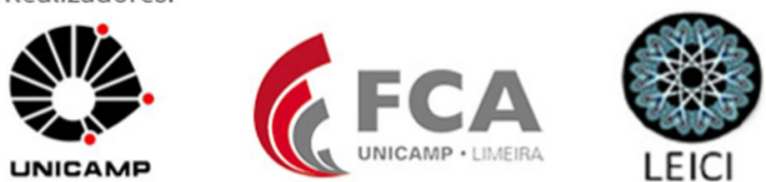


\subsubsection{Caso 04: Fase de Lançamento}

A quarta empresa que compõe a amostra, é considerada pelo entrevistado 04, de acordo com as características das etapas de Borges, Filion e Simard (2008) que lhes foi apresentada como condizente com a de lançamento. Em seu relato, ele informou experiências anteriores com outras startups e relatou ter identificado outras oportunidades mais interessantes. Então, resolveu migrar de um negócio, em que era o único desenvolvedor da parte tecnológica, para formar uma outra equipe, buscando o compartilhamento das novas atividades. Diante desta, relata também que sua visão atual, o seu negócio (FILION, 1991) é uma adaptação de um outro modelo. Isso se aproxima de uma adaptação ao cotidiano e de um processo de socialização do conhecimento, denotando que a vivência anterior o motivou a buscar trabalho em equipe, o que é corroborado por determinados autores (FILION, 1991; ZHANG, 2011; CROWNE, 2002).

O entrevistado demonstra uma fala curta e objetiva sobre o aprendizado, novas tecnologias e feedbacks recebidos. Estes aspectos estão observados em Ries, 2012. Na opinião do entrevistado o aprendizado é destacado como relevante para novos projetos, ou seja, futuramente lhe será um agregador, conforme relata: “(...) Com certeza o aprendizado vai ser utilizado para esse e novos projetos. Consigo entender como o todo funciona, encontrar as lacunas."

Enfatiza a ação de reflexão presentes, como sugere Pimentel (2007) e o controle de seus próprios processos, conforme fala: “(...) Uma vez que se conhece o caminho, é menos difícil passar por ele novamente." Esta última fala demonstra representar a percepção que permeia empreendedores que após ter vivenciado experiências, e contribuem para o aprendizado atual, referendado por Cope; Watts (2000) e Politis (2005).

\section{Considerações Finais}

Esta pesquisa objetivoubuscar evidências nas empresas pesquisadas de aprendizagem experiencial no processo de criação de startups de base tecnológica a partir do conhecimento sobre o perfil e a etapa de criação de cada empreendimento. Cada etapa, orientada por Borges, Filion e Simard (2008), está definida como conjunto de atividades que o empreendedor realiza para conceber, organizar e lançar uma empresa.

As etapas com as devidas características foram apresentadas aos entrevistados para que pudessem conforme a sua realidade, identificar a proposição teórica do desenvolvimento da empresa de base tecnológica. Dentre as quatro etapas, duas empresas caracterizaram-se na fase de preparação e duas na fase de lançamento.

As perguntas foram formuladas de acordo com a literatura teórica e base empírica do aprendizado experiencial nas organizações. Por meio das entrevistas foi possível traçar características semelhantes entre as empresas como, por exemplo, a visão de negócio (FILION, 1991); a vivência de experiências empresariais anteriores, e principalmente captar a percepção de cada empresário sobre o processo de aprendizagem individual.

Observou-se similaridades entre as percepções dos entrevistados. Dentre as mais comuns verificou-se a presença de características motivacionais do empreendedor, a percepção dos erros durante o processo que os beneficiam em projetos futuros, bem como o

Organizadores:

- FGV EAEsp
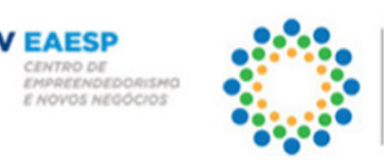

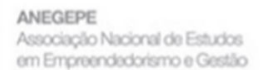

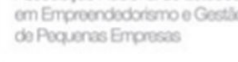

Realizadores:
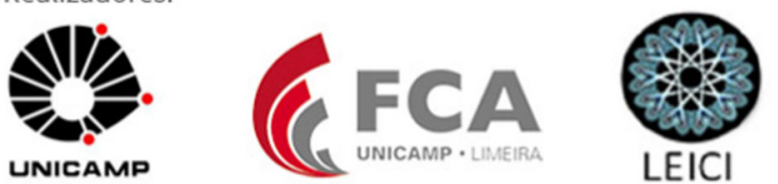
reconhecimento da aprendizagem experiencial na atividade empreendedora, o que pode ser corroborado pelos autores Cassar e Graig (2009) e Arruda; Nogueira; Cozzi e Costa (2012).

Outro ponto marcante e diferenciado nas experiências apresentadas foi o processo de se aprender com o feedback do cliente, assim como sugerido por Ries (2012), denotando a busca pela qualidade de gestão.

Nota-se, portanto, que todos os empreendedores confirmaram ter tido experiências empresariais, mesmo não sendo na atuação em startups, como no caso 03 , bem como, relataram ter vivenciado tanto experiências de sucesso quanto de fracasso nos negócios em que atuaram, como mencionado pelo entrevistado do caso 01 .

As características das startups apresentadas no que se refere à juventude e imaturidade (SUTTON, 2000); processo de pesquisa e construção e crescimento (BLANK, 2015) e a visão de Ries (2012) na ótica de construir, medir e aprender se mostraram perceptíveis na fala dos entrevistados e coerentes com as quatro etapas apresentadas por Borges, Filion e Simard (2008). Destaca-se também que o processo contínuo de aprendizagem evidenciado por Kolb (1984) e a ação e reflexão proposta por Pimentel (2007) foram corroboradas no relato dos casos apresentados.

Pelo exposto, evidenciou-se, na percepção dos entrevistados, a relevância do aprendizado para empresas nascentes de base tecnológicas - startups - uma vez que estas, pela sua forma de criação e desenvolvimento aproximam os empreendedores dos clientes, enfatizando-se a importância do trabalho em equipe, bem como os erros e falhas que são percebidos tanto para os próximos projetos quanto para adequação dos atuais.

Dentre as limitações do trabalho, estão o quantitativo de respondentes e o foco apenas no processo de criação e, principalmente, o fato de que dentre as quatro etapas apresentadas, apenas duas foram contempladas pelos entrevistados.

Para futuras pesquisas, poderá ser realizado um aprofundamento das características específicas do processo de aprendizado organizacional, com foco em gestão, desenvolvimento de competências e estratégias empresariais.

Considerando-se que o estudo de empresas de base tecnológica se mostra crescente no Brasil e sabendo-se que há ambiente fértil em empreendedorismo, espera-se que esta pesquisa possa contribuir para novos estudos, bem como para o processo de conhecimento de gestão de negócios caracterizados como startups.

\section{Referências}

ARRUDA, Carlos et al. Causas Da Mortalidade De Startups Brasileiras. O que fazer para aumentar as chances de sobrevivência no mercado, 2012.

BITENCOURT, Claudia Cristina. A gestão de competências gerenciais: a contribuição da aprendizagem organizacional. 2001.

BLANK, S. (2015) The Global Startup Ecosystem Ranking. The Startup Report Ecosystem Series. Compass.co. 2015

BLANK, Steve; DORF, Bob. Startup: manual do empreendedor. Alta Books Editora, 2014. BORGES, Cândido. O papel do capital social do empreendedor na criação de empresas tecnológicas. RAI Revista de Administração e Inovação, v. 8, n. 3, p. 162-181, 2011.

\section{Organizadores:}

FGV EAESP

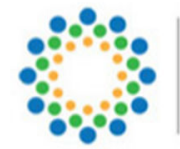

ANEGEPE

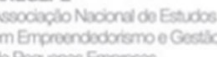

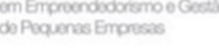
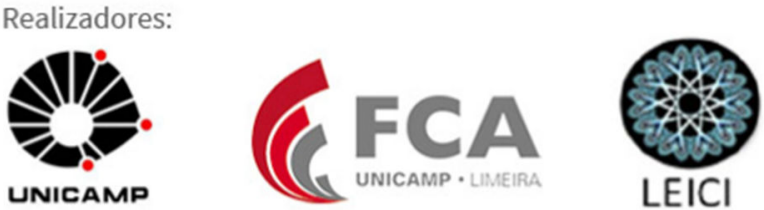
BORGES, Cândido; FILION, Louis Jacques; SIMARD, Germain. Jovens empreendedores e o processo de criação de empresas. Revista de administração Mackenzie, v. 9, n. 8, 2009.

BRESLIN, Dermot; JONES, Colin. The evolution of entrepreneurial learning. International Journal of Organizational Analysis, v. 20, n. 3, p. 294-308, 2012.

BRÜDERL, Josef; PREISENDÖRFER, Peter; ZIEGLER, Rolf. Survival chances of newly founded business organizations. American sociological review, p. 227-242, 1992.

CHESBROUGH, Henry. Business model innovation: it's not just about technology anymore. Strategy \& leadership, v. 35, n. 6, p. 12-17, 2007.

GATEWOOD, Elizabeth J.; SHAVER, Kelly G.; GARTNER, William B. A longitudinal study of cognitive factors influencing start-up behaviors and success at venture creation. Journal of business venturing, v. 10, n. 5, p. 371-391, 1995.

CASSAR, Gavin; CRAIG, Justin. An investigation of hindsight bias in nascent venture activity. Journal of Business Venturing, v. 24, n. 2, p. 149-164, 2009.

COPE, Jason; WATTS, Gerald. Learning by doing-an exploration of experience, critical incidents and reflection in entrepreneurial learning. International Journal of Entrepreneurial Behavior \& Research, v. 6, n. 3, p. 104-124, 2000.

CROWNE, Mark. Why software product startups fail and what to do about it. Evolution of software product development in startup companies. In: Engineering Management Conference, 2002. IEMC'02. 2002 IEEE International. IEEE, 2002. p. 338-343.

Conference, 2002. IEMC'02. 2002 IEEE International (Vol. 1, pp. 338-343). IEEE.

FILION, Louis Jacques. O planejamento do seu sistema de aprendizagem empresarial: identifique uma visão e avalie o seu sistema de relações. Revista de Administração de Empresas, v. 31, n. 3, p. 63-71, 1991.

FILION, Louis Jacques. Empreendedorismo: empreendedores e proprietários-gerentes de pequenos negócios. Revista de administração, v. 34, n. 2, p. 5-28, 1999.

GASQUE, Kelley Cristine Gonçalves Dias. O papel da experiência na aprendizagem: perspectivas na busca e no uso da informação. 2008.

GATEWOOD, Elizabeth J.; SHAVER, Kelly G.; GARTNER, William B. A longitudinal study of cognitive factors influencing start-up behaviors and success at venture creation. Journal of business venturing, v. 10, n. 5, p. 371-391, 1995.

GIARDINO, Carmine et al. What do we know about software development in startups?. IEEE software, v. 31, n. 5, p. 28-32, 2014.

ILLERIS, Knud. What do we actually mean by experiential learning? Human Resource Development Review, v. 6, n. 1, p. 84-95, 2007.

GODOY, Arlida Schmidt. Introdução à pesquisa qualitativa e suas possibilidades. Revista de administração de empresas, v. 35, n. 2, p. 57-63, 1995.

KOLB, David. Experiential education: Experience as the source of learning and development. 1984.

MAIA, Tatiane Silva Tavares; LIMA, Edmilson. Aprendizagem e decisão estratégica realizadas por equipes de direção em pequenas empresas. Revista ReGePe, 5.3: 59-89, 2016.

MIZUMOTO, Fábio Matuoka et al. A sobrevivência de empresas nascentes no estado de São Paulo: um estudo sobre capital humano, capital social e práticas gerenciais. Revista de Administração, v. 45, n. 4, p. 343-355, 2010.

Organizadores:

- FGV EAESP

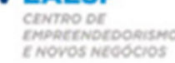

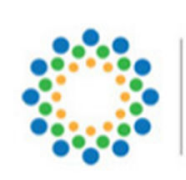

ANEGEPE

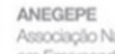

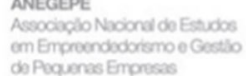
co Provernes Emproses
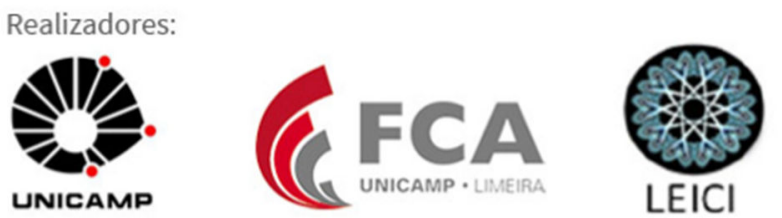
PIMENTEL, Alessandra. A teoria da aprendizagem experiencial como alicerce de estudos sobre desenvolvimento profissional. Estudos de psicologia, v. 12, n. 2, p. 159-168, 2007.

POLITIS, Diamanto. The process of entrepreneurial learning: A conceptual framework. Entrepreneurship theory and practice, v. 29, n. 4, p. 399-424, 2005.

RAE, David. Understanding entrepreneurial learning: a question of how? International Journal of Entrepreneurial Behavior \& Research, v. 6, n. 3, p. 145-159, 2000.

RIES, Eric. A startup enxuta: como os empreendedores atuais utilizam a inovação contínua para criar empresas extremamente bem-sucedidas. São Paulo: Lua de Papel, 2012.

ROESCH, Sylvia Maria Azevedo et al. Projetos de estágio e de pesquisa em administração. São Paulo: Atlas, v. 2, 1999.

SANDBERG, Jörgen. Understanding human competence at work: an interpretative approach. Academy of management journal, v. 43, n. 1, p. 9-25, 2000.

SONG, Michael et al. Success factors in new ventures: A meta-analysis. Journal of product innovation management, v. 25, n. 1, p. 7-27, 2008.

SUTTON, Stanley M. The role of process in software start-up. IEEE Software, v. 17, n. 4, p. 33-39, 2000.

TRIVIÑOS, Augusto Nibaldo Silva. Introdução à pesquisa em ciências sociais: a pesquisa qualitativa em educação. O positivismo; a fenomenologia; o marxismo. In: Introdução à pesquisa em ciências sociais: a pesquisa qualitativa em educação. $O$ positivismo; a fenomenologia; o marxismo. Atlas, 2006.

VAN DE VEN, Andrew H.; HUDSON, Roger; SCHROEDER, Dean M. Designing new business startups: Entrepreneurial, organizational, and ecological considerations. Journal of management, v. 10, n. 1, p. 87-108, 1984.

ZHANG, Junfu. The advantage of experienced start-up founders in venture capital acquisition: Evidence from serial entrepreneurs. Small Business Economics, v. 36, n. 2, p. 187-208, 2011. VAN GELDEREN, Marco; THURIK, Roy; BOSMA, Niels. Success and risk factors in the prestartup phase. Small Business Economics, v. 26, n. 4, p. 319-335, 2006.

YIN, Robert K. Estudo de Caso-: Planejamento e Métodos. Bookman editora, 2015. 